\title{
Asynchronous Online Simulation in Nursing Education: Creating Learning Opportunities to Meet Current Challenges
}

\author{
Sandie Nadelson, RN, MSN, MSEd, PhD, CHSE ${ }^{1^{*}}$, Louis Nadelson, PhD ${ }^{2}$, Kelley Connor, R.N., MSN, PhD, CHSE ${ }^{3}$ \\ ${ }^{1}$ Assistant Professor, Department of Health Science, School of Nursing, University of Central Arkansas, 201 Donaghey Ave, Conway Arkansas, \\ 72035, United States. \\ ${ }^{2}$ Associate Professor, Department Chair, University of Central Arkansas, College of Education, 201 Donaghey Ave, Conway Arkansas, \\ 72035, United States. \\ ${ }^{3}$ Associate Professor, School of Nursing, Boise State University, 1910 University Dr. Boise, ID 83725, United States.
}

Article Details
Article Type: Review Article
Received date: $06^{\text {th }}$ December, 2021
Accepted date: $29^{\text {th }}$ December, 2021
Published date: $30^{\text {th }}$ December, 2021

"Corresponding Author: Sandie Nadelson, RN, MSN, MSEd, PhD, CHSE, Assistant Professor, Department of Health Science, School of Nursing, University of Central Arkansas, 201 Donaghey Ave, Conway Arkansas, 72035, United States. E-mail: snadelson1@uca.edu

Citation: Nadelson, S., Nadelson, L., \& Connor, K. (2022). Asynchronous Online Simulation in Nursing Education: Creating Learning Opportunities to Meet Current Challenges. J Comp Nurs Res Care 7(1):177. doi: https://doi.org/10.33790/ jenrc1100177.

Copyright: $\mathbb{C} 2022$, This is an open-access article distributed under the terms of the Creative Commons Attribution License 4.0, which permits unrestricted use, distribution, and reproduction in any medium, provided the original author and source are credited.

\begin{abstract}
Online simulations are growing in popularity to reduce the reliance on clinical sites and simulation laboratories to enhance students' skills and abilities. Many nursing programs are investigating how to expand their online simulation offerings. Deciding on the best online simulation modality for enhancing learning can be difficult as many options are available. Choices include performing simulations "live" in "real-time," called synchronous learning or asynchronous, which means this happens when the instructors and other students may not be present. In deciding how to increase programs' simulation offerings, options for online asynchronous simulations include developing your own simulations, utilizing no-cost web-based simulations, or purchasing access to previously developed online simulations offered by proprietary companies. Each online simulation type has benefits and limitations. In this article, we cover the pros and cons of these options. The information about online asynchronous simulations included will assist nurse educators in making informed choices to meet their targeted learning outcomes.
\end{abstract}

Key Words: Simulation, Nursing Student, Nurse, Online, Education, Professional Development

\section{Introduction}

The use of simulation has been an option to enhance learning in nursing education for several decades. However, the reliance on simulation for instruction and the possibilities for creating and implementing simulations is expanding rapidly [1]. In this article, we will describe a variety of simulation options available for nursing programs. Before delving into the benefits and considerations of different choices for simulation, we will define and describe synchronous and asynchronous engagement in simulations in the context of nursing education.

Synchronous simulations commonly occur in a location (frequently considered a simulation laboratory) that has been created to look like an actual clinical setting such as a clinic, home, or hospital. The locations often have mannequins and other simulated human body parts which are used to practice health-care-related procedures and hone decision-making skills. The synchronous simulation in these locations involves students making care choices and practicing care while being mentored by their instructors [2]. Thus, when involved with the synchronous simulation, students learn at scheduled times.

Asynchronous simulations are most commonly online and computer-based, in which students are provided with scenarios and prompted for responses. For example, a student may be provided with patient data and asked to assess the patient's condition. Unlike synchronous simulations, in asynchronous simulations, feedback by faculty members and assessments of students' performance may not occur during or just after the simulation. However, with advanced technology, immediate computer-generated feedback is more common.

\section{Exploring Simulation Options}

Due to multiple factors, simulation in nurse preparation and professional development continues to expand and evolve. Simulation experiences take many forms for students and nursing staff. Research indicates that synchronous simulation learning experiences are beneficial for helping learners develop new skills, practice techniques, and engage in critical thinking [2]. The long history of success of synchronous simulations has made them widely used in nursing education. However, synchronous simulation centers or laboratories tend to be cost-intensive to create and maintain. Further, simulation laboratories have limited space, which constrains the number of learners engaged in simulations for learning simultaneously. Thus, the instructors of many nursing and staff development programs continue to explore the cost and timeeffective alternatives for creating, offering, and expanding student engagement in simulated learning experiences [3].

A current trend in health care education is to supplement synchronous laboratory-based simulations with online asynchronous simulations [4]. Motivating the change is opportunities for increased access to learning from simulations and lower operation costs. Digital simulation learning experiences is classified in two ways: synchronous and asynchronous.

Online simulations can be very effective for helping learners develop and hone their clinical decision-making [5]. In addition, online 
simulations are useful in helping students develop their professional skills such as communication, ethics, and interdisciplinary collaboration [6]. Thus, online simulations are readily used to engage students in role-playing, role modeling, discussions, case study analyses, and games. The structure of online simulations may include videos of patient situations and a series of questions for students to answer related to the assessment and response to the patient. Students may engage in online simulations individually, in pairs, or groups. Online simulations can be completed outside of usual student learning time, such as evenings and weekends, depending on the course objectives and schedule. It is also possible to have students complete online simulations during the scheduled classroom or clinical times. Perhaps the most significant benefit of online simulations is that they are implemented to be asynchronous, providing flexibility and extended opportunities for learning. Regardless of the implementation, there can be challenges with locating, integrating and implementing online simulations.

Finding quality online simulations that meet the learning objectives of the nursing education programs can be challenging [7]. Many commercial products are purchased, some online simulations that are open access, and tools for creating online simulations. The challenge is to select the approach that aligns with the expectations of the education provider (e.g., within budget, accessible, customizable) while also meeting the learning needs of the students.

In recognition of the potential challenges with selecting and implementing online simulations, we explore the typical configurations of online simulations currently available for nursing education. We also gathered information on the costs, ease of adoption, the flexibility of scenarios, and interactivity of online simulations. The information included in our report can inform nursing educators' process of choosing and implementing online asynchronous simulations that best meet their students' and programs' needs.

\section{Online Simulation Overview}

As mentioned previously, there are many forms and uses of simulation in nursing education. A growing number are being offered asynchronously and utilized outside the traditional simulation laboratory [8]. In the following few paragraphs and in Table 1, we provide some details of the common types of asynchronous online simulations. We include a brief description of each and some positive and negative aspects. In addition, we provide links to some webbased online simulation resources to help explore sites of interest.

\begin{tabular}{|c|c|c|c|c|}
\hline Type of Simulation & \begin{tabular}{|l|} 
Ease of Adoption \\
and/or Development
\end{tabular} & Monetary Costs & \begin{tabular}{|l} 
Flexibility of \\
Scenarios
\end{tabular} & nteractive \\
\hline $\begin{array}{l}\text { Online Lab Simulation } \\
\text { with } \\
\text { "homegrown" } \\
\text { scenarios }\end{array}$ & $\begin{array}{l}\text { Moderate to } \\
\text { intensive depending } \\
\text { on the skill level of } \\
\text { faculty and staff. } \\
\text { It may require } \\
\text { significant training. }\end{array}$ & $\begin{array}{l}\text { Low with } \\
\text { technological savvy, } \\
\text { knowledgeable } \\
\text { faculty and Staff }\end{array}$ & $\begin{array}{l}\text { Many different types } \\
\text { of scenarios can be } \\
\text { developed and used }\end{array}$ & Yes \\
\hline Teacher Moments & $\begin{array}{l}\text { Low investment in } \\
\text { time and training }\end{array}$ & $\begin{array}{l}\text { Low: Minimal costs } \\
\text { related time for } \\
\text { faculty and staff to } \\
\text { develop scenarios }\end{array}$ & $\begin{array}{l}\text { Many unique types } \\
\text { of scenarios can be } \\
\text { developed, used, and } \\
\text { quickly altered }\end{array}$ & $\begin{array}{l}\text { Yes, students speak } \\
\text { to the computer }\end{array}$ \\
\hline $\begin{array}{l}\text { YouTube \& Google } \\
\text { Forms Use }\end{array}$ & $\begin{array}{l}\text { Low investment in } \\
\text { time and training }\end{array}$ & $\begin{array}{l}\text { Low: Costs related } \\
\text { to the development } \\
\text { time by faculty and } \\
\text { staff }\end{array}$ & $\begin{array}{l}\text { Many diverse } \\
\text { scenarios can be } \\
\text { developed, used, and } \\
\text { quickly altered } \\
\end{array}$ & $\begin{array}{l}\text { Some interaction } \\
\text { through digital } \\
\text { choices }\end{array}$ \\
\hline $\begin{array}{l}\text { Virtual Healthcare } \\
\text { Experience (Ryerson } \\
\text { U) }\end{array}$ & $\begin{array}{l}\text { Meager investment } \\
\text { in time and training }\end{array}$ & $\begin{array}{l}\text { Very low: No } \\
\text { development needed } \\
\& \text { no fees }\end{array}$ & $\begin{array}{l}\text { Few scenarios } \\
\text { available and not } \\
\text { adaptable }\end{array}$ & $\begin{array}{l}\text { Yes, through digital } \\
\text { choices }\end{array}$ \\
\hline $\begin{array}{l}\text { Proprietary } \\
\text { Simulations (e.g., } \\
\text { i-Human, vSim, } \\
\text { Shadow Health, } \\
\text { SentinelU)) }\end{array}$ & $\begin{array}{l}\text { Low investment in } \\
\text { time and training }\end{array}$ & $\begin{array}{l}\text { Low: If learners pay } \\
\text { the fee } \\
\text { Moderate: If the } \\
\text { nursing program } \\
\text { covers the fee }\end{array}$ & $\begin{array}{l}\text { A limited number } \\
\text { of scenarios are } \\
\text { available that often } \\
\text { are not easily altered }\end{array}$ & $\begin{array}{l}\text { It varies, but most } \\
\text { are interactive }\end{array}$ \\
\hline
\end{tabular}

\section{"Homegrown"}

Nurse educators were instrumental in the initial development of online simulations. Faculty members who developed the simulations relied on their personal clinical experiences to create scenarios and explored a range of online options for implementing the simulations [9]. When "homegrown" simulations are reviewed and updated frequently, they help support student learning [10]. Unfortunately, there are drawbacks to using homegrown online simulations, such as expertise, time, and technology support [9].

Before moving forward with homegrown online simulation development, a key consideration is that many faculty members do not have the time, skills, or ability to write quality online simulations. Developing online activities takes considerable time and knowledge [9]. Even adapting a previously created lab scenario to a place where it is usable online can be a complicated process. The development requires faculty to acquire a working understanding of simulation educational principles and online programming. As a result, nurse educators who want to be online simulation developers need support which may be an additional expense that needs to be covered.

However, certain approaches to developing and implementing homegrown online simulations can be relatively easy and may be considered viable options under the right conditions. Developing homegrown online simulations may be possible through the creative repurposing of commonly accessible software such as Power Point or Google. Because of the relatively low preparation costs, online simulations created using normally accessible software homegrown scenarios tend to be less expensive to develop. Another positive aspect of homegrown online simulations is that the cases are more easily modified or created to align with specific learning goals than simulations purchased from proprietary companies. 


\section{Resources for Developing Asynchronous Online Learning}

Open Access Simulation Case Studies. A common practice is for nursing education programs to find open access (no-cost) case studies and alter them to meet their students' needs and learning goals. Numerous pre-developed scenarios are easily changed to make them usable online as either synchronously or asynchronously. The use of the existing scenarios reduces the development costs of time, resources, and expertise. Some free and easily accessed scenarios that can be adapted for online asynchronous learning are found at the following websites:

https://www.skillscommons.org/handle/taaccet/15215, https:// www.sim-one.ca/scenario, https://ksbn.kansas.gov/administratorresources/simulation-scenarios/

Teacher Moments: After case studies scenarios are initially created or identified, nursing simulation faculty and staff can develop online simulations using several platforms for delivering text, audio, videos, and graphics [10]. A free platform called "Teacher Moments" (sponsored by the Massachusetts Institute of Technology - https:// teachermoments.mit.edu/) is open access easy to use interface for developing and offering online simulations. Using Teacher Moments, faculty members can provide scenario content, prompt students with questions, and allow students to answer by typing or verbally recording their responses. The Teacher Moments' interface translates the audio input into text when the students respond verbally. When the students respond verbally, the output from the simulations is both the recorded audio and the translated text. Instructors can easily download the output data for assessment or research if they choose. The link to a simulation we created and have used to teach ethical decision making is found here:

\section{https://teachermoments.mit.edu/run/1108742f0c/slide/0}

YouTube and Google Forms: Another way to develop online simulations involves using a combination of YouTube videos and Google Forms. The faculty members or staff create the patient care-related YouTubes videos simulations and link responses to prompts for the learners to answer in Google Forms. Developers can design the forms so that Google Forms score them, and then the students' responses and scores can be accessed by instructors. If faculty members already know how to use YouTube and Google Forms, creating online simulations using these two resources will be easy. Further other than the development time, there are no additional costs associated with using YouTube and Google Forms for online simulations.

\section{Free Pre-Developed Online Simulations}

Homegrown online simulations can be advantageous for multiple reasons, but as we have shared, the simulations require knowledge and time to create and maintain. An alternative to developing homegrown online simulations is to access existing ones that others have created. There are multiple websites where nursing instructors can access free online simulations. We think that the following two sites are worth considering for adoption.

Several years ago, a website was developed by nursing instructors at Montgomery College. The site is often used as it includes free videos and additional supporting documents focused on patient care issues. The simulation documents include copies of charts and medical orders. The site is located at:

https://www.montgomerycollege.edu/academics/departments/ nursing-tpss/nursing-simulation-scenario-library.html

Second, nursing instructors at Ryerson University created a website populated with high-quality interactive online simulations. The online simulations take the form of a "game" associated with various healthcare-related scenarios. The simulations are structured to allow students to make choices. The feedback provided to users is related to how the learners respond to questions. There is no fee associated with using online simulations. There are multiple simulations with different themes that can be accessed at https://de.ryerson.ca/games/.
The direct link to the hospital focused simulation is https://de.ryerson. ca/games/nursing/hospital/

\section{Proprietary Simulations}

Motivated by the shifts in learning in response to efforts to mitigate the spread of COVID-19, several companies, such as Elsevier, have expanded the number of purchasable online simulations [1]. There are multiple advantages to purchasing online simulations, such as quickly having a solution to keep students engaged in learning when needing to reduce the number of students using on ground laboratory spaces. The purchased online simulations can potentially reduce the costs of providing classroom or laboratory-based simulations. Further, purchasing developed simulations alleviates the time needed to create and maintain homegrown simulations. The fee to access proprietary simulations is usually the responsibility of the users who are often students. The cost shift to the user reduces the expense of running the simulations incurred by nurse education programs. In addition, most of the online propriety simulation ready to be implemented, so preparation for using the simulations of nursing faculty and staff tends is very low. Typically, the faculty and staff preparation needed for using the simulations is associated with accessing the scenarios and the records of their students' performance. Some providers of proprietary online simulations include SimPulse, i-Human, vSim, Shadow Health, and SentinelU.

\section{Summary of Online Simulations}

As we have shared, online simulations tend to be useful for asynchronous teaching and learning. Online simulations allow learners to practice and develop a range of skills. The platforms we have shared gather data from the users that instructors can access for assessment of students' learning. In Table 1 we summarize some of the fundamental features of online simulations, which may be helpful when considering the best option for adopting and using online simulation for teaching and learning.

\section{Conclusion}

Asynchronous simulation can be a valuable tool for teaching future and current health care providers. Many simulation resources are available for learners, faculty members, and simulation staff. Choosing the right one to meet the needs of the learners can be facilitated by knowing what is available, what are the costs and benefits of each. Before choosing a particular simulation for online asynchronous teaching and learning, we recommend exploring multiple options to determine what fits your teaching goals and needs best.

Competing Interests: Author report no conflict or competing interest.

\section{List of Abbreviations: $U$ = University Acknowledgements: None \\ References}

1. MacRae, D., Jara, M.R., Tyerman, J., Luctkar-Flude, M. (2021). Investing in Engagement: Integrating Virtual Learning Experiences across an Undergraduate Nursing Program. Clinical Simulation in Nursing. 52:17-32.

2. Roye, J., Anderson, M., Diaz, D.A., Rogers, M. (2021). Considerations for the Effective Integration of Virtual Simulation in the Undergraduate Nursing Curriculum. Nursing Education Perspectives. 42(6):E173-5.

3. Atthill, S., Witmer, D., Luctkar-Flude, M., Tyerman, J. (2021). Exploring the impact of a virtual asynchronous debriefing method after a virtual simulation game to support clinical decision-making. Clinical Simulation in Nursing. 2021 Jan 1;50:10-8.

4. Foronda, C.L., Fernandez-Burgos, M., Nadeau, C., Kelley, C.N., Henry, M.N. (2020). Virtual simulation in nursing education: a systematic review spanning 1996 to 2018. Simulation in Healthcare. 15(1):46-54. 
5. Belliston, S.L. (2020). The Effect of Asynchronous Versus Synchronous Online Course Delivery on HESI Scores and Student Engagement for Rural Pre-Licensure Nursing Students (Doctoral dissertation, University of Nevada, Las Vegas).

6. Bartlett J.L., Kinsey J.D. (2020). Large-group, asynchronous, interprofessional simulation: Identifying roles and improving communication with student pharmacists and student nurses. Currents in Pharmacy Teaching and Learning. 12(6):763-70.

7. Huun K. (2018). Virtual simulations in online nursing education: Align with quality matters. Clinical Simulation in Nursing, 1(22), 26-31.
8. Fogg, N., Wilson, C., Trinka,M., Campbell, R., Thomson, A., Merritt, L., Tietze, M., \& Prior, M. (2020). Transitioning from direct care to virtual clinical experiences during the COVID-19 pandemic. Journal of Professional Nursing, 36(6):685-91.

9. Hughey, D., \& Maaks, D.L. (2020). A cost-effective solution to video debriefing and livestreaming in nursing simulation. Clinical Simulation in Nursing, 48:15-9.

10. Nadelson, S., Conner, K., Nadelson, L., Gray, R., \& Griffith, K. (2021). Using an asynchronous open-source platform for leadership education. Sigma Repository. https://sigma. nursingrepository.org/bitstream/handle/10755/22199/Abstract. pdf? sequence $=6 \&$ is Allowed $=y$ 